\title{
Does the depth of gastric ulceration influence a modified dual therapy with amoxicillin and lansoprazole for Helicobacter pylori- associated gastric ulcer?
}

\author{
Takashi Okai MD, Koushiro Ohtsubo MD, Junta Sakai MD, Hiroyuki Watanabe MD, \\ Yoshiharu Motoo MD, Atsuhiro Kawashima MD, Norio Sawabu MD
}

T Okai, K Ohtsubo, J Sakai, et al. Does the depth of gastric ulceration influence a modified dual therapy with amoxicillin and lansoprazole for Helicobacter pylori-associated gastric ulcer? Can J Gastroenterol 2000;14(9):761-766.

PURPOSE: To clarify whether the depth of ulceration evaluated by endoscopic ultrasonography (EUS) influences a modified dual therapy with amoxicillin and lansoprazole for the treatment of Helicobacter pylori-positive patients with gastric ulcer.

PATIENTS AND METHODS: Twenty-two consecutive cases of gastric ulcer (nine superficial ulcers and 13 deep ulcers) in $H$ pylori-positive patients were studied. Ten of 22 patients received a two-week eradication therapy with amoxicillin $1500 \mathrm{mg} /$ day, lansoprazole $30 \mathrm{mg} /$ day and a new antiulcer agent with features in common with sucralfate, ecabet sodium, $2.0 \mathrm{~g} /$ day. They continued to receive the same doses of lansoprazole and ecabet sodium for the next six weeks. The other 12 patients received the same therapy except for those who underwent the four-week amoxicillin treatment. All patients underwent EUS both at the start of the study and eight weeks later. They then received ecabet sodium alone for the next six months as a maintenance therapy, followed by a six-month interval with no treatment. The final endoscopy was done one year after $H$ pylori eradication therapy was completed to evaluate $H$ pylori status and ulcer recurrence.

RESULTS: The rates of endoscopic healing and H pylori eradication in the nine patients with superficial ulcer were $100 \%$, irrespective of the period of amoxicillin treatment. In contrast, the rates of endoscopic evidence of healing and $\mathrm{H}$ pylori eradication in the 13 patients with deep ulcer were different for each period of amoxicillin treatment; that is, the rates of reduction in ulcer determined by echo and $H$ pylori eradication in the four patients treated with the two-week amoxicillin course were significantly lower $(\mathrm{P}=0.03)$ than those in the nine patients treated with the fourweek course.

CONCLUSION: Ulcer depth is likely to influence the success of amoxicillin treatment for $\mathrm{H}$ pylori-positive patients with gastric ulcer.

Key Words: Amoxicillin; Depth of gastric ulcer; Ecabet sodium, Endoscopic ultrasonography; Eradication therapy; Helicobacter pylori; Lansoprazole

Pour le résumé, voir page suivante

Department of Internal Medicine and Medical Oncology, Cancer Research Institute, Kanazawa University, Kanazawa, Japan

Correspondence and reprints: Dr Takashi Okai, Department of Internal Medicine and Medical Oncology, Cancer Research Institute,

Kanazawa University, 4-86 Yoneizumi, Kanazawa 921-8044, Japan. Telephone +81-76-226-2511, fax +81-76-226-2539,

e-mail okai@kenroku.kanazawa-u.ac.jp

Received for publication September 20, 1999. Accepted April 26, 2000 


\section{La profondeur de l'ulcère influe-t-elle sur la bithérapie modifiée, composée d'amoxicilline et de lansoprazole pour le traitement de l'ulcère gastro-duodénal associé à Helicobacter pylori?}

BUT : Déterminer si la profondeur de l'ulcère, évaluée à l'échographie endoscopique (EE) influe sur la bithérapie modifiée, composée d'amoxicilline et de lansoprazole pour le traitement de l'ulcère gastro-duodénal associé à Helicobacter pylori.

PATIENTS ET MÉTHODE : Vingt-deux patients consécutifs souffrant d'un ulcère gastro-duodénal ( 9 superficiels et 13 profonds) associé à $H$. pylori ont participé à l'étude. Dix des vingt-deux patients ont été soumis à un traitement d'éradication d'une durée de deux semaines, composé de $1500 \mathrm{mg} /$ jour d'amoxicilline, de $30 \mathrm{mg} /$ jour de lansoprazole et d'un nouvel agent anti-ulcéreux qui partage des propriétés en commun avec le sucralfate, l'ecabet sodique, à raison de 2,0 g/jour. Ces patients ont continué à recevoir les mêmes doses de lansoprazole et d'ecabet sodique durant les six semaines suivantes. Les 12 autres patients ont été soumis au même traitement, sauf pour ce qui est de l'antibiothérapie à l'amoxicilline, qui a duré quatre semaines. Tous les patients ont subi une EE au début de l'essai et huit semaines plus tard. Par la suite, ils ont pris de l'ecabet sodique seul durant six mois à titre de traitement d'entretien, suivi d'une autre période de six mois sans traitement. Une dernière endoscopie a été pratiquée un an après la fin du traitement d'éradication d'H. pylori pour évaluer la présence de la bactérie et la récurrence des ulcères.

RÉSULTATS : Le taux de cicatrisation observée à l'endoscopie et d'éradication d'H. pylori chez les 9 patients souffrant d'un ulcère superficiel a été de $100 \%$, indépendamment de la durée du traitement à l'amoxicilline. Par contre, ce taux chez les 13 patients souffrant d'un ulcère profond variait selon la durée du traitement à l'amoxicilline : il était, chez les 4 patients soumis au traitement à l'amoxicilline d'une durée de deux semaines, sensiblement inférieur $(\mathrm{p}=0,03)$ à celui enregistré chez les 9 patients soumis au traitement de quatre semaines.

CONCLUSION : La profondeur de l'ulcère constitue vraisemblablement un facteur susceptible d'influer sur le traitement à l'amoxicilline de l'ulcère gastro-duodénal associé à $H$. pylori.
$\mathrm{I}^{\mathrm{n}}$ n 1993, Labenz et al (1) first reported that a two-week course of therapy with amoxicillin and omeprazole was the most effective schedule for the eradication of Helicobacter pylori in patients with ulcer disease. Since then, most of the dual therapies including amoxicillin have been tried with the same treatment schedule; that is, amoxicillin was always administered for two weeks and never for longer than two weeks. Chiba et al (2) reported that eradication rates for dual therapy with amoxicillin and proton pump inhibitors were not more than 70\%. In 1998, Tanimura et al (3) reported that the eradication rates of $\mathrm{H}$ pylori in patients with peptic ulcers increased proportionally with the length of amoxicillin treatment (two, four and six weeks), while the healing rates did not change. Therefore, it is worth reconsidering whether the two-week treatment is actually the best schedule for dual therapy with amoxicillin, although the reason for the unexpected increase in eradication rates of peptic ulcers after amoxicillin treatment was prolonged to four or six weeks is poorly understood.

In clinical practice, endoscopy or barium meal $x$-ray study is used to evaluate the nature of peptic ulcer diseases. Niwa et al $(4,5)$ were the first to demonstrate the utility of endoscopic ultrasonography (EUS) for evaluating the depth of ulceration. They used this new imaging modality to evaluate the healing of gastric ulcer and demonstrated that omeprazole offered advantages over cimetidine in the treatment of gastric ulcer (4). Namely, it was clarified that the ulcer floor had shrunk greatly, with endoscopic regression of the ulcer crater with the use of omeprazole. An advantage of lansoprazole over famotidine in gastric ulcer treatment has been shown in the same manner (6). It is thus possible to evaluate gastric ulcer healing from the depth of ulceration by using EUS, which provides cross-sectional images of the ulcer, coupled with endoscopic observations of the ulcer surface.

Previous studies using endoscopy failed to demonstrate a relation between the depth of gastric ulceration and the suc- cess of $H$ pylori eradication in $H$ pylori-positive patients with gastric ulcer (7-12). Consequently, it is not clear whether the depth of ulcer affects the eradication of $H$ pylori during therapy for $\mathrm{H}$ pylori-positive patients with gastric ulcer (13). In the present study, we addressed this problem by using EUS. We then considered whether two weeks of amoxicillin treatment was the best schedule for dual therapy with amoxicillin.

\section{PATIENTS AND METHODS}

Patients: The study population comprised 22 patients treated consecutively in whom gastric endoscopy and biopsy revealed $H$ pylori-associated gastric ulcer at the outpatient clinic of Internal Medicine and Medical Oncology, Kanazawa University Cancer Research Institute Hospital, Kanazawa, Japan, between September 1994 and April 1998. There were 18 men and four women, and the mean age of the study population was 54.5 years (range 36 to 70 years). $\mathrm{Pa}$ tients were excluded if they used acetylsalicylic acid or other nonsteroidal anti-inflammatory drugs (NSAID), or if gastric biopsy from the ulcer revealed malignancy. The institutional review board of the Kanazawa University Cancer Research Institute approved the study, and all patients gave their written informed consent.

Methods: All 22 patients with H pylori-associated gastric ulcer underwent a modified triple therapy with amoxicillin, lansoprazole and ecabet sodium for two or four weeks. Ecabet sodium is a new, locally acting antiulcer agent with features in common with sucralfate $(14,15)$. Ten patients entered between September 1994 and May 1996 received a two-week eradication therapy with amoxicillin $1500 \mathrm{mg} /$ day, lansoprazole $30 \mathrm{mg} /$ day and ecabet sodium $2.0 \mathrm{~g} /$ day. After completing this therapy, the patients stopped taking amoxicillin but continued to receive the same doses of lansoprazole and ecabet sodium for the next six weeks. During the initial study performed between September 1994 and 

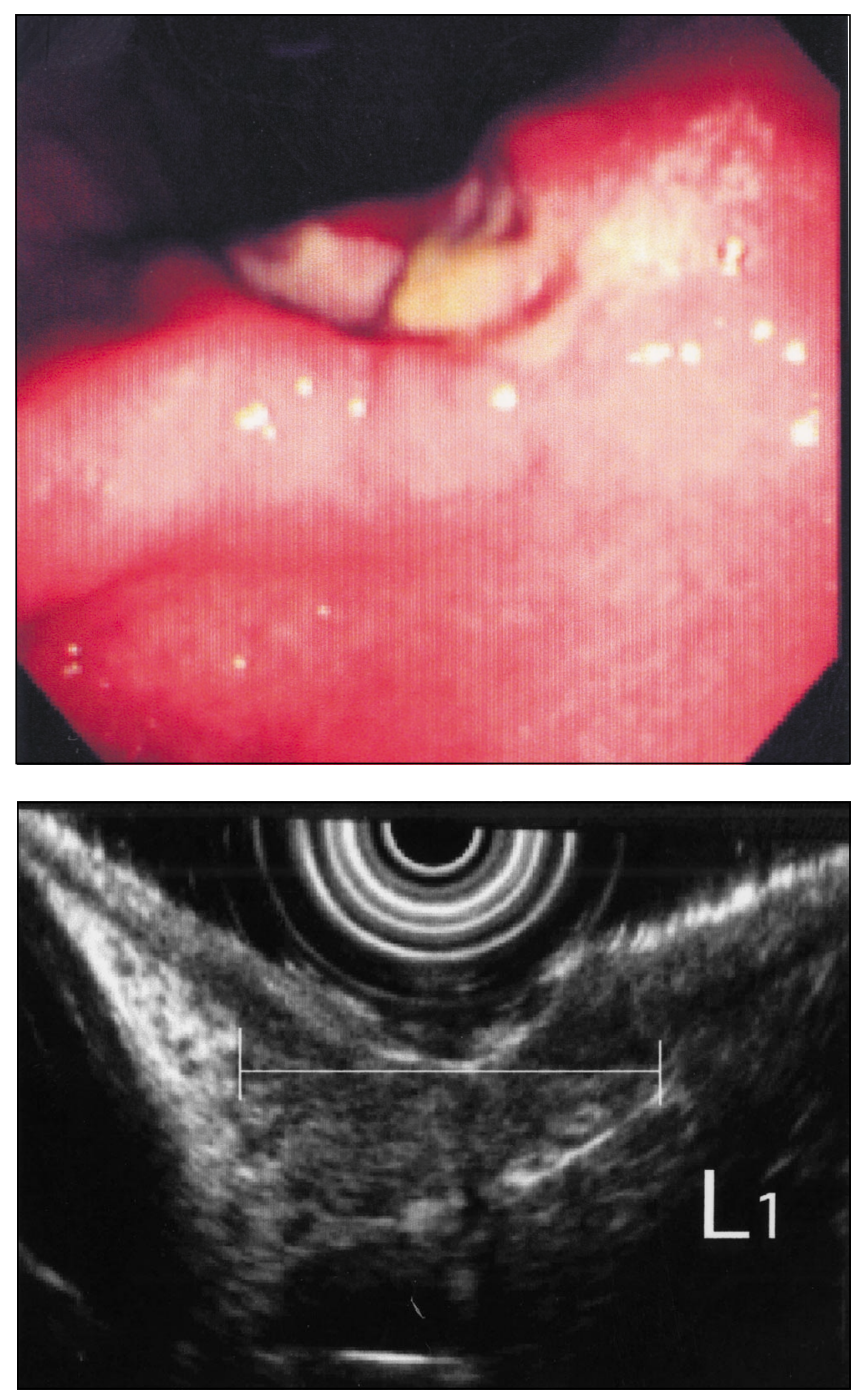

Figure 1) Endoscopic and endosonographic features before (left) and after (right) eight-week eradication therapy. Percentage reduction of ulcer echo by endosonic ultrasonography was calculated as follows: percentage reduction of ulcer echo $=\left(L_{1}-L_{2}\right) / L_{1} \times 100(\%)$, where $L_{1}=$ length of the ulcer echoes at the beginning of eradication therapy and $L_{2}=$ length of the ulcer echoes eight weeks after the start of eradication therapy

May 1996, two-week amoxicillin treatment was found to be inadequate for the patients with deep gastric ulcer. Thus, the protocol was changed to a four-week amoxicillin treatment in the next 12 patients entered between June 1996 and April 1998. They received the same doses of lansoprazole and ecabet sodium during a four-week eradication therapy with amoxicillin $1500 \mathrm{mg} /$ day. After receiving this therapy, they also stopped taking amoxicillin and continued to receive the same doses of lansoprazole and ecabet sodium for the next four weeks. Consequently, an eight-week drug therapy was given in both groups as an initial treatment for $\mathrm{H}$ pyloriassociated gastric ulcer.

All patients were sequentially followed for six months, during which time ecabet sodium $2.0 \mathrm{~g} /$ day was continued as a maintenance therapy. To confirm ulcer recurrence and the absence of $H$ pylori, the patients who healed at the end of the initial treatment underwent routine gastrointestinal endoscopy after a second six-month follow-up period without medications.
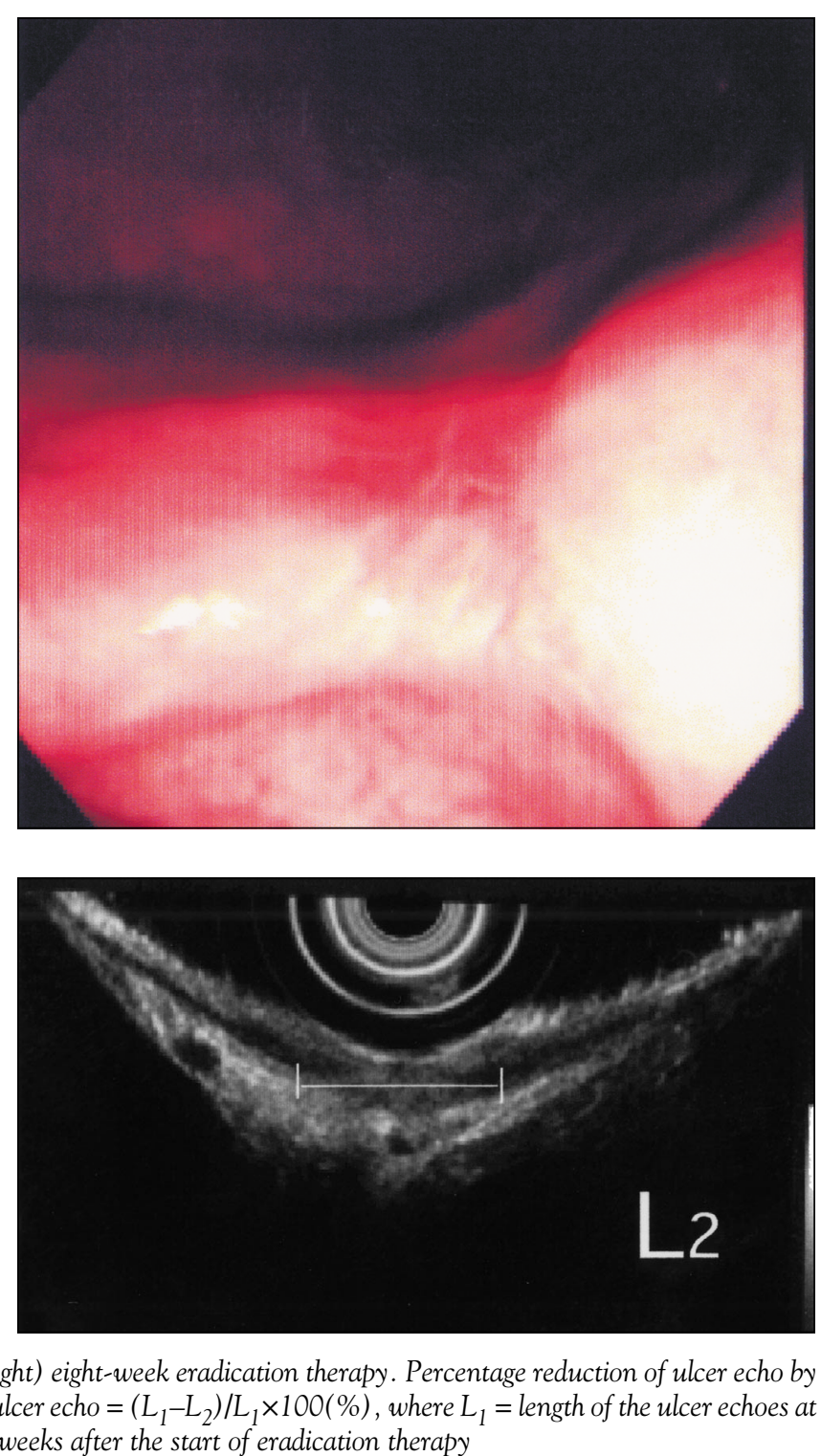

EUS was performed at the start of treatment and again eight weeks later. A GF-UM200 EUS (Olympus Co Ltd, Japan) was used to evaluate the depth of ulcer as well as endoscopic healing. The maximal sections of ulcerative lesions were imaged after pouring 400 to $800 \mathrm{~mL}$ of deaerated water into the gastric lumen (Figure 1). By using EUS, both sectional and endoscopic images of gastric ulcer were obtained at one endoscopic examination, and thereby the treatment effects of each therapy were evaluated in detail. The depth of ulcer was classified into three grades: Ul-II, which involves the submucosal layer; Ul-III, which involves the proper muscle layer; and Ul-IV, which penetrates the proper muscle layer and involves the serosa (4). Grades Ul-II and Ul-III were combined to include superficial ulcer, because Ul-III ulcer has proved to have a similar quality to Ul-II ulcer and is clearly different from Ul-IV ulcer. The maximum length of the ulcer-derived low echoic zone was measured, and the rate of reduction in these 'ulcer echoes' was calculated as described by Niwa et al $(4,5)$ and Okai et al (6) (Figure 1). 
TABLE 1

Correlation between the rate of endoscopic healing and depth of ulcer, according to the length of treatment with amoxicillin

Endoscopic healing (\%)

\begin{tabular}{lccc} 
Treatment period & UI-II and UI-III ulcers & UI-IV ulcers & P \\
\hline Two weeks & $6 / 6(100 \%)$ & $1 / 4(25 \%)^{*}$ & 0.03 \\
Four weeks & $3 / 3(100 \%)$ & $7 / 9(78 \%)^{*}$ & 0.54 \\
\hline
\end{tabular}

$* P=0.11$

TABLE 2

Correlation between the percentage reduction of ulcer echoes and depth of ulcer, according to the length of treatment with amoxicillin

\begin{tabular}{lccc}
\hline & \multicolumn{3}{c}{$\begin{array}{c}\text { Percentage ulcer reduction } \\
\text { seen on echo } \\
\text { (mean } \pm \text { SE) }\end{array}$} \\
Treatment period & UI-II and UI-III ulcers & UI-IV ulcers & P \\
\hline Two weeks & $79.2 \pm 7.3^{*}$ & $50.6 \pm 4.9^{* *}$ & 0.02 \\
Four weeks & $78.7 \pm 1.3^{*}$ & $69.8 \pm 4.8^{* *}$ & 0.27 \\
\hline
\end{tabular}

${ }^{*} P=0.96,{ }^{*} P=0.03$

On gastric biopsy, if the ulcer proved to be nonmalignant, a set of three biopsy specimens was collected from two different sites - the greater curvatures at the antrum and the upper body of the stomach. Using these specimens, rapid urease test (CLO test, Delta West Pty Ltd, Australia), culture test on Skirrow's medium and histological examination under a microscope after Giemsa, and hematoxylin and eosin staining were performed. When positive findings were detected in culture and by any other test, $H$ pylori infection was diagnosed. Eradication was defined as no evidence of ongoing $H$ pylori infection by all the tests.

Fisher's exact test and nonpaired $t$ test were used to compare values in subgroups of patients. The Bonferroni correction for multiple comparisons was applied to all probability values reported. $\mathrm{P}<0.05$ was considered significant.

\section{RESULTS}

Endoscopic healing eight weeks after the start of treatment: Table 1 shows the rates of endoscopic healing eight weeks after the start of treatment in each group. The rate of healing in the patients with superficial ulcer (Ul-II or Ul-III) was 100\%, irrespective of the period of amoxicillin treatment. On the other hand, the rate in the patients with deep ulcer (Ul-IV) was significantly lower if the treatment period with amoxicillin was limited to two weeks $(\mathrm{P}=0.03)$, although it was improved when the period was extended to four weeks.

Endosonographic assessment of ulcer healing eight weeks after the start of treatment: Table 2 shows the rates of reduction in ulcer echoes eight weeks after the start of treatment in each group. The rates of reduction were higher in the patients with superficial ulcer (Ul-II or Ul-III) than in those with deep ulcer (Ul-IV). The difference was significant when
TABLE 3

Correlation between the rate of Helicobacter pylori eradication and the depth of ulcer, according to the length of treatment with amoxicillin

Rate of eradication (\%)

\begin{tabular}{lccc} 
Treatment period & UI-II and UI-III ulcers & UI-IV ulcers & P \\
\hline Two weeks & $6 / 6(100 \%)$ & $1 / 4(25 \%)^{*}$ & 0.03 \\
Four weeks & $3 / 3(100 \%)$ & $7 / 9(78 \%)^{*}$ & 0.54 \\
\hline
\end{tabular}

$* P=0.11$

amoxicillin was administered for two weeks $(\mathrm{P}=0.02)$. However, even in patients with deep ulcer, the rates of reduction in ulcer echoes were significantly higher if the period of amoxicillin administration was changed to four weeks $(\mathrm{P}=0.03)$.

Eradication rate of $H$ pylori six months after the cessation of ecabet sodium treatment: Table 3 shows the rate of $H$ pylori eradication six months after the cessation of ecabet sodium. The eradication rates accurately corresponded to the rates of endoscopic healing. The rate of $\mathrm{H}$ pylori eradication in the patients with superficial ulcer (Ul-II or Ul-III) was $100 \%$, irrespective of the period of amoxicillin treatment. On the other hand, the $\mathrm{H}$ pylori eradication rate in the patients with deep ulcer (Ul-IV) was significantly lower if amoxicillin treatment was limited to two weeks $(\mathrm{P}=0.03)$, although it was improved when treatment was extended to four weeks.

Recurrence rate six months after the cessation of ecabet sodium treatment: To confirm ulcer recurrence, the $17 \mathrm{pa}$ tients whose ulcers had healed at the end of the initial treatment underwent routine gastrointestinal endoscopy during ecabet sodium treatment and six months after ecabet sodium treatment. Only one patient's superficial ulcer recurred during the follow-up. This recurrence was discovered by chance at the initial follow-up. The patient had been receiving a NSAID for severe lumbago since finishing the initial eightweek treatment. He had no abdominal complaints. He discontinued the NSAID treatment and underwent famotidine treatment. A repeat endoscopy was performed after one month, and the ulcer proved to have healed. His $\mathrm{H}$ pylori status remained negative until the final follow-up. Consequently, if this patient were excluded, the rates of ulcer recurrence during the follow-up period would be $0 \%$, irrespective of the ulcer depth and the period of amoxicillin treatment.

Clinical symptoms and adverse effects: Epigastric pain disappeared within two weeks of treatment in most patients. No patient experienced any side effects such as diarrhea, watery stool or exanthema. Furthermore, no abnormalities were found in laboratory findings. Thus, there were no differences in effects and adverse effects related to treatment.

\section{DISCUSSION}

In the present study, EUS was used to evaluate whether the depth of ulcer affects the eradication of $H$ pylori in a therapy for $\mathrm{H}$ pylori-associated gastric ulcer. The depth of ulcer was 
shown to affect the eradication of $H$ pylori; that is, the rates of $\mathrm{H}$ pylori eradication as well as of endoscopic healing in the patients with deep gastric ulcer were low, while the rates were $100 \%$ in those with superficial ulcer. These results suggest that ulcer depth is an important factor influencing both endoscopic healing and $\mathrm{H}$ pylori eradication. Furthermore, in this study, the rates of both endoscopic healing and $\mathrm{H} p \mathrm{py}$ lori eradication were improved by increasing the length of amoxicillin treatment to four weeks, even if the patients had a deep ulcer. This finding suggests that the duration of amoxicillin treatment should be adjusted in proportion to the depth of the ulcer. Accordingly, this finding may be the key to answering the question of why eradication rates increase unexpectedly after the period of amoxicillin treatment is prolonged, as was shown in a recent clinical study (3).

Kamada et al (16) and Sato et al (17) disclosed that gastric mucosal blood flow at an active phase of chronic gastric ulcer was reduced in most regions of the stomach. They demonstrated that the blood flow returned to normal during healing, although it was disproportionately higher around the gastric ulcer than in the surrounding mucosa. Furthermore, they clarified that the mucosal blood flow was not increased at the healing stage in intractable ulcers that did not heal after three months of therapy with $\mathrm{H}_{2}$-receptor antagonists (16). Consequently, it may be assumed that the mucosal blood flow in patients with deep ulcers, which heal slowly (13), is likely to be lower than that in patients with a superficial ulcer, during the course of healing as well as at onset. Using an $\mathrm{H}$ pylori-infected mouse model of acetic acid-induced ulcer, Konturek et al (18) showed that the rise in gastric blood flow both at the ulcer crater and at the ulcer margin was significantly slowed on inoculation of a virulent $\mathrm{H}$ pylori strain, resulting in a delay in ulcer healing. Therefore, it is possible that the status of $H$ pylori at the gastric mucosa also affects the increase of gastric mucosal blood flow during

\section{REFERENCES}

1. Labenz J, Gyenes E, Ruhl GH, Borch G. Omeprazole plus amoxicillin: Efficacy of various treatment regimens to eradicate Helicobacter pylori. Am J Gastroenterol 1993;88:491-5.

2. Chiba N, Wilkinson JM, Hunt RH. Clarithromycin (C) or amoxicillin (A) dual and triple therapies in H.pylori (Hp) eradication: a meta-analysis. Gut 1995;37(Suppl 2):T124.

3. Tanimura H, Kawano S, Kubo M, et al. Does Helicobacter pylori eradication depend on the period of amoxicillin treatment? A retrospective study. J Gastroenterol 1998;33:23-6.

4. Niwa Y, Nakazawa S, Tsukamoto Y, et al. A new method for evaluating gastric ulcer healing by endoscopic ultrasonography. Scand J Gastroenterol 1991;26:457-64.

5. Niwa Y, Nakazawa S, Yoshino J, et al. Quantification of gastric ulcer healing by endoscopic ultrasonography. Gastrointest Endosc 1990;36:116-22.

6. Okai T, Sawabu N, Songur Y, Motoo Y, Watanabe H. Comparison of lansoprazole and famotidine for gastric ulcer by endoscopic ultrasonography: A preliminary trial. J Clin Gastroenterol 1995;20(Suppl 2):S32-5.

7. Graham DY, Lew GM, Klein PD, et al. Effect of treatment of Helicobacter pylori infection on the long-term recurrence of gastric or duodenal ulcer. A randomized, controlled study. Ann Intern Med 1992;116:705-8.

8. Labenz J, Borsch G. Evidence for the essential role of Helicobacter pylori in gastric ulcer disease. Gut 1994;35:19-22. treatment. As for drug delivery, on the other hand, Goddard et al (19) reported that the flux of amoxicillin from the blood to the gastric lumen is lower than that of metronidazole because the serum protein binds to amoxicillin more tightly. Therefore, under conditions of reduced gastric mucosal blood flow, such as with deep ulceration or positive $H$ pylori infection, amoxicillin should be administered for as long as possible to obtain and maintain susceptible antibiotic concentrations in the gastric mucosa. These data concerning gastric blood flow, $\mathrm{H}$ pylori status and transmucosal flux of antibiotics help to explain why it took as long as four weeks to treat the patients with deep gastric ulcer in the present study.

In the present study, ecabet sodium, a new locally acting antiulcer agent with antipeptic activity, gastroprotective effects $(14,15)$, and antiurease action of $H$ pylori in vitro $(20)$, was administered via dual therapy with lansoprazole and amoxicillin to promote healing and $\mathrm{H}$ pylori eradication (21). However, given the present study design, the therapeutic effect of ecabet sodium itself could not be assessed. Because a randomized, controlled study (21) showed that significantly higher rates of $H$ pylori eradication were attained with minimal side effects of diarrhea by the addition of ecabet sodium to usual dual therapy with lansoprazole plus amoxicillin (21), further studies with a large number of patients are warranted. The number of patients enrolled in this study is too small to determine the true clinical significance of this new combined therapy with three agents.

\section{CONCLUSIONS}

Ulcer depth is likely to influence a modified therapy with amoxicillin and lansoprazole for the treatment of $\mathrm{H}$ pyloriassociated gastric ulcer. When using amoxicillin, which has not been reported to cause resistance and is cost effective (22), the administration period should be adjusted according to the depth of the ulcer.

9. Sung JJ, Chung SC, Ling TK, et al. Antimicrobial treatment of gastric ulcers associated with Helicobacter pylori. N Engl J Med 1995;332:139-42.

10. Bayerdorffer E, Miehlke S, Lehn N, et al. Cure of gastric ulcer disease after cure of Helicobacter pylori infection - German gastric ulcer study. Eur J Gastroenterol Hepatol 1996;8:343-9.

11. Axon AT, O'Morain CA, Bardhan KD, et al. Randomized double blind controlled study of recurrence of gastric ulcer after treatment for eradication of Helicobacter pylori infection. BMJ 1997;314:565-8.

12. Van der Hulst RW, Rauws EA, Koycu B, et al. Prevention of ulcer recurrence after eradication of Helicobacter pylori: a prospective longterm follow-up study. Gastroenterology 1997;113:1082-6.

13. Okada M, Yao T, Imamura K, et al. Factors influencing the healing rate of gastric ulcer under treatment with cimetidine. Am J Gastroenterol 1989;84:501-5.

14. Onoda Y, Magaribuchi T, Tamaki H. Effects of 12-sulfodehydroabietic acid monosodium salt (TA-2711), a new anti-ulcer agent, on gastric secretion and experimental ulcers in rats. Jpn J Pharmacol 1989;51:65-73.

15. Kinoshita M, Yamasaki K, Kokusenya Y, Tamaki H. Relationship between gastroprotective effect of locally acting antiulcer agent ecabet sodium and its binding to gastric mucosa in rats. Dig Dis Sci 1995;40:661-7.

16. Kamada T, Kawano S, Sato N, Fukuda M, Fusamoto H, Abe H. 


\section{Okai et al}

Gastric mucosal blood distribution and its changes in the healing process of gastric ulcer. Gastroenterology 1983;84:1541-6.

17. Sato N, Kawano S, Tsuji S, Ogihara T, Yamada S. Gastric blood flow in ulcer diseases. Scand J Gastroenterol Suppl 1995;208:14-20.

18. Konturek PCH, Brzozowski T, Konturek SJ, et al. Mouse model of Helicobacter pylori infection: studies of gastric function and ulcer healing. Aliment Pharmacol Ther 1999;13:333-46.

19. Goddard AF, Erah PO, Barrett DA, et al. The effect of protein binding and lipophilicity of penicillins on their in-vitro flux across gastric mucosa. J Antimicrob Chemother 1998;41:231-6.
20. Shibata K, Ito Y, Hongo A, Yasoshima A, Endo T, Ohashi M. Bactericidal activity of a new antiulcer agent, ecabet sodium, against Helicobacter pylori under acidic conditions. Antimicrob Agents Chemother 1995;39:1295-9.

21. Ohkusa T, Takashimizu I, Fujiki K, et al. Prospective evaluation of a new anti-ulcer agent, ecabet sodium, for the treatment of Helicobacter pylori infection. Aliment Pharmacol Ther 1998;12:457-61.

22. Peterson WL, Graham DY, Marshall B, et al. Clarithromycin as monotherapy for eradication of Helicobacter pylori: a randomized, double-blind trial. Am J Gastroenterol 1993;88:1860-4. 


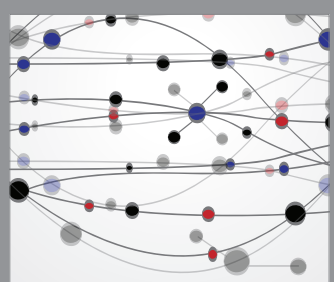

The Scientific World Journal
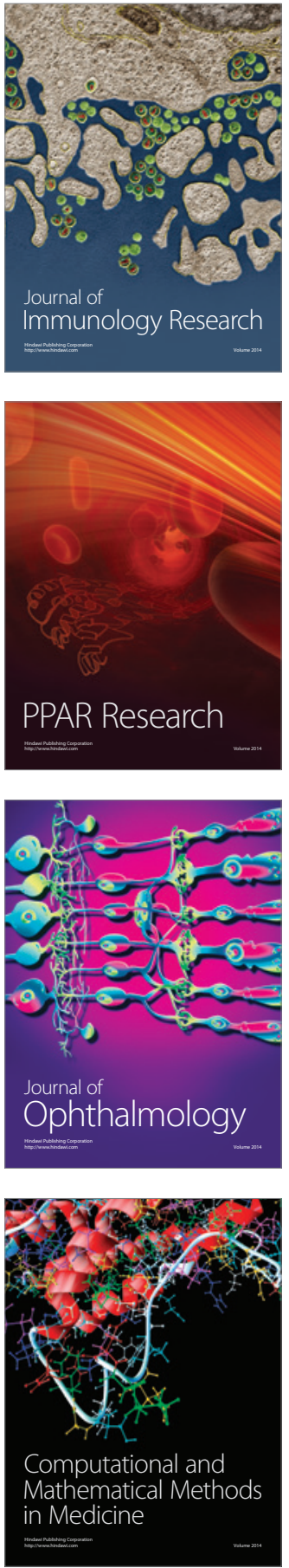

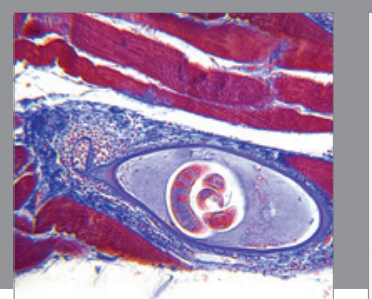

Gastroenterology Research and Practice

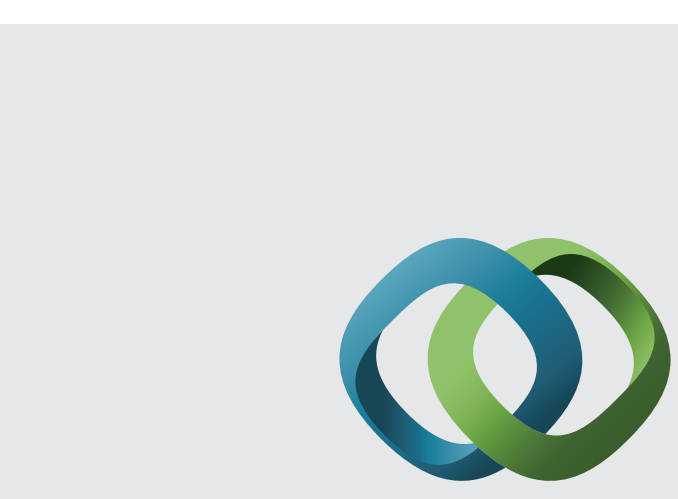

\section{Hindawi}

Submit your manuscripts at

http://www.hindawi.com
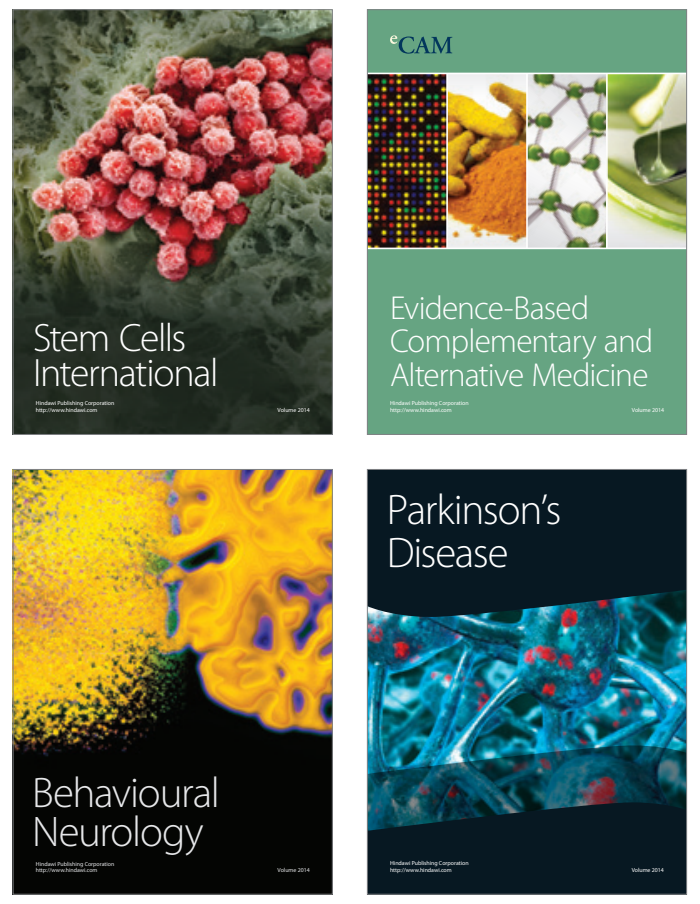
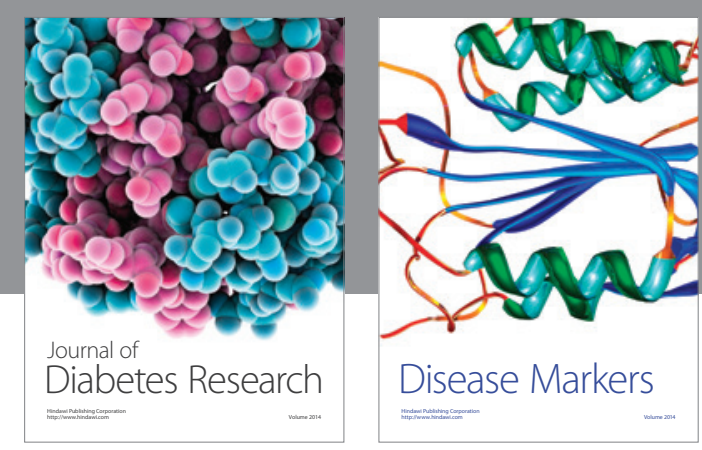

Disease Markers
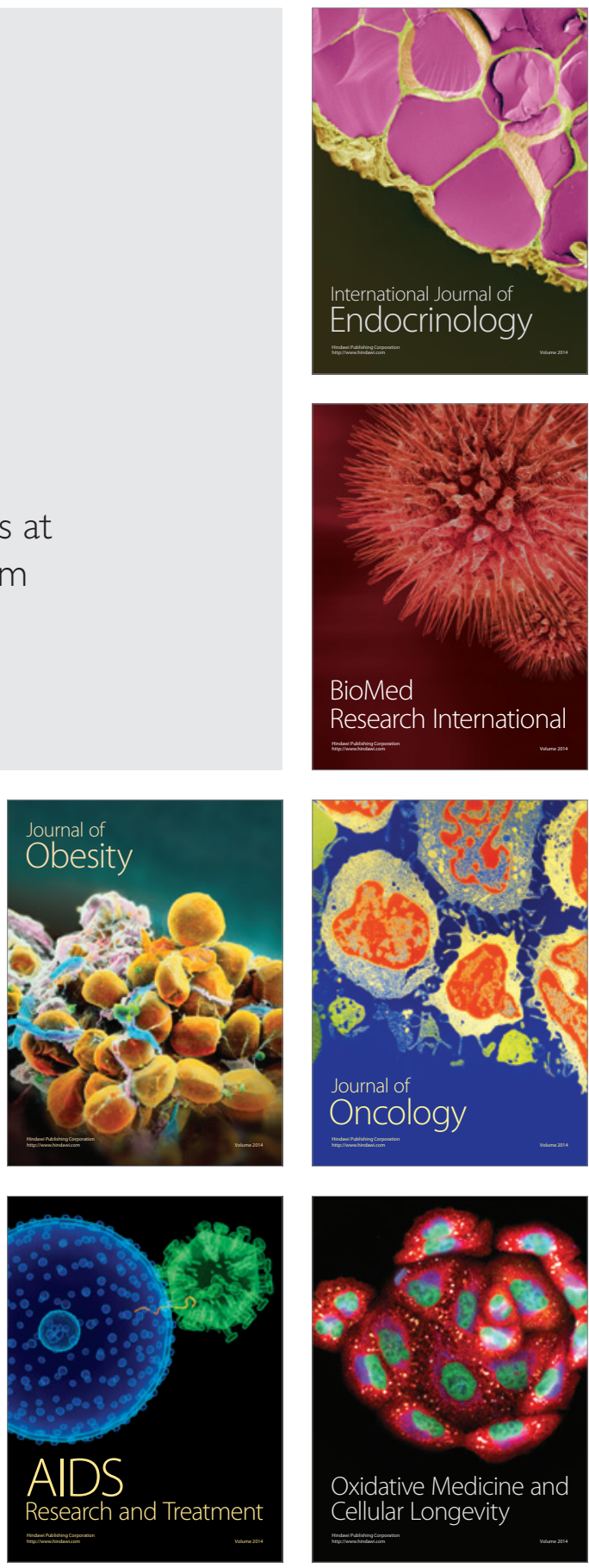